\title{
POLICE PERCEPTIONS OF ADHD IN YOUTH INTERVIEWEES
}

\author{
Kimberley J. Cunial \& Mark R. Kebbell \\ School of Applied Psychology \\ Griffith University
}

Address for correspondence:

School of Applied Psychology

Griffith University

Mt Gravatt Campus

Queensland, 4111

Australia

kimberley.cunial@griffithuni.edu.au 


\begin{abstract}
Attention Deficit Hyperactivity Disorder (ADHD) in witness-victim/suspect interviews holds strong relevance for policing. Four purpose-written vignettes were used to test the extent to which ADHD interviewee behaviour impacts on the work of 46 experienced Australian detectives and their ability to identify ADHD as a likely diagnosis. Detectives reported frequently encountering ADHD-type interviewees in their work; perceiving such interviewees to be at a very significant risk of future contact with the Criminal Justice System; and perceiving ADHD-type behaviour to exert a highly significant impact on interviewing time efficiency as well as quality. Detectives gave highly significant ratings of ADHD as a likely explanation of vignettes describing ADHD type behaviour for witness-victims as well as suspects. However, they could not identify ADHD as the most likely explanation over and above other possibilities. Implications are discussed in terms of a rationale for future research targeting police awareness and training needs in ADHD.
\end{abstract}

Keywords: ADHD, youth, police, interviewing, vignette 


\section{Introduction}

Attention-Deficit/Hyperactivity Disorder (ADHD) is a common childhood disorder with neuro-developmental deficits (McArdle, 2004). There is definitive neurological evidence that these deficits, as evidenced by structural and functional brain abnormalities, contribute to problems with response inhibition, response variability, working memory, attention, verbal and non-verbal fluency, impulse control, timing-related behaviour, temporal discounting, planning and problem-solving (Barkley, 2015). The DSM-5 (American Psychiatric Association, 2013) classifies ADHD as a persistent pattern of at least six symptoms of inattentive and/or impulsive behaviours continuing for at least six months, more frequently/severely observed than in age-matched peers, impairing functioning in at least two settings, impacting social, academic or occupational functioning, and not accounted for by another disorder or failure to understand instructions/tasks. Epidemiological studies show an excess of males affected by ADHD, with a ratio of 3-4 males per female in the general population and 7-8 males to each female in clinical populations (Thapar \& Cooper, 2016). Each child presents differently (Sparrow \& Erhardt, 2014). Some children outgrow their symptoms (Young \& Gudjonsson, 2007, 2008). Yet the condition often persists (Ginsberg, Hirvikoski, \& Lindefors, 2010; Thapar \& Cooper, 2016) with pooled prevalence rates with the general population estimated at 5.29\% for youth (Polanczyk et al., 2007), and 2.5\% for adults (Simon et al., 2009). Rates are more pervasive in offender populations, with estimates of $30.1 \%$ in youth prison populations and $26.2 \%$ in adult prison populations (Young et al., 2015).

Youth with ADHD, particularly when undetected or untreated, may face a negative trajectory of outcomes including academic failure, truancy, performance problems, neuropsychological impairments, anxiety, depression, substance abuse, obsessive compulsions, poor socialization, family conflicts, dysfunctional relationships, poor planning 
and decision-making, behavioural difficulties, car accidents and physical injuries (Gudjonsson, Sigurdsson, Sigfusdottir, \& Young, 2011; Young \& Gudjonsson, 2007; Young, Wells, \& Gudjonsson, 2011). There is also a trajectory to a high rate of contact with the criminal justice system (CJS) (Young, Wells et al., 2011), and this may be related to developing antisocial problems (DeLisi, Neppl, Lohman, Vaughn, \& Shook, 2013). There are high personal, social and financial costs to the individual with ADHD and to society. Youth with ADHD proceeding along this negative trajectory are costly to manage and rehabilitate (Ginsberg, Langstrom, Larsson, \& Lichtenstein, 2013).

Many people with ADHD come into early contact with the CJS, and whilst countless go undiagnosed, studies show high numbers (up to 67\%) of prison inmates being retrospectively diagnosed with childhood ADHD and remaining symptomatic (Einarsson, Sigurdsson, Gudjonsson, Newton, \& Bragason, 2009; Young \& Gudjonsson, 2005). ADHD, along with conduct disorder, is the most frequently recorded diagnosis in forensic settings (Lindsay et al., 2010). ADHD has been associated with onset of criminal behaviour from a young age (see Lambie, Ione, Randell, \& Seymour, 2013), putting individuals at risk for lifecourse persistent offending (Lindsay et al., 2013; Young, Adamou et al., 2011; Young et al., 2015). Individuals with ADHD are more likely to recidivate, offend faster than other reoffenders, and their ADHD is the strongest predictor of increased and earlier police contact as well as a trajectory to anti-social problems and imprisonment even when controlling for comorbid factors (see Collins \& White, 2002; Gudjonsson, Wells, \& Young, 2011; Young \& Gudjonsson, 2007).

Youth with ADHD are highly vulnerable interviewees. Being a child or adolescent increases suggestibility, disadvantage and poor coping throughout every stage of the judicial process, especially when younger due to their difficulty with free recall over cued recall, trouble identifying the source of their beliefs, eagerness to please or agree, and high 
deference to interviewers perceived as authoritarian (see Powell \& Lancaster, 2003; Powell \& Snow, 2007). ADHD behaviours hold strong forensic relevance, which make affected youth highly vulnerable (Gudjonsson, Young, \& Bramham, 2007). A credible witness must be willing and able to provide accurate, reliable and complete information (Kebbell \& Wagstaff, 1996; Kebbell, Milne, \& Wagstaff, 1999). Yet research shows youth with ADHD have executive function deficits, and such deficits make it difficult to emotionally cope, attend to relevant cues, remember all question parts and reply choices, provide coherent and accurate answers, resist yielding and contamination errors, as well as to inhibit their disproportionately frequent “don’t know” responses, culpable statements and false information/confessions (Gudjonsson, 2010, 2012; Gudjonsson, Sigurdsson, Bragason, Newton, \& Einarsson, 2008; Gudjonsson, Sigurdsson, Sigfusdottir, \& Young, 2011; Gudjonsson, Sigurdsson, Einarsson, Bragason, \& Newton, 2010; Young, Goodwin, Sedgwick, \& Gudjonsson, 2013).

The literature shows that poor memory is associated with heightened suggestibility, which is linked to yielding and false information/confessions (Milne, Sharman, Powell, \& Mead, 2013; Powell \& Thomson, 1997; Read, Powell, Kebbell, \& Milne, 2009). Managing such deficits leads many individuals with ADHD to emotional lability and reliance on maladaptive coping strategies, further heightening suggestibility and vulnerability (Howard \& Seok Hong, 2002; Goldstein, 1997; Young, 2005). This holds a range of implications for the judicial process (Collins \& White, 2002; Goldstein, 1997; Vrij, Granhag, \& Porter, 2010). Practitioners should be mindful that misremembering is different to lying (Vrij et al., 2010), and to instead adopt a developmental approach (Bala, Lee, \& McNamara, 2001; Brubacher, Glisic, Roberts, \& Powell, 2011).

The functional deficits associated with ADHD, heightened in younger interviewees, may impact detectives’ ability to conduct good interviews. The behavioural disinhibitions, emotional lability, as well as propensity for “don’t know” responses and false 
information/confessions are demanding of staff resources beyond conduct disorder and intellectual impairment (Young et al., 2013). Behavioural characteristics associated with ADHD may lead police to misread cues, examine wrong cues, assume uncooperativeness or evasiveness, presume guilt or deception, neglect inter/intra personal differences, needlessly rush and interrupt interviewees, undermine confidence, excessively repeat questions, overuse closed or leading questions, use opinion statements, apply pressure, be coercive, fail to establish rapport and steer away from best practice techniques during interviewing (Gudjonsson \& Sigurdsson, 2010; Vrij et al., 2010). The literature suggests best practice is less likely to be used when any interviewee is perceived as uncooperative (Griffiths, Milne, \& Cherryman, 2011; Read et al., 2009; Snook, Luther, Quinlan, \& Milne, 2012), and this may perpetuate the use of minimal/misleading responses (Milne \& Bull, 2003; Milne, Sharman, Powell, \& Mead, 2013). Inappropriate interviewing techniques may raise questions about accuracy of information, form the bases of legal challenge, lead to mistrial, induce harsher sentencing and/or false imprisonment, and represent a miscarriage of justice (Collins \& White, 2002; Griffiths \& Milne, 2010; Griffiths, Milne, \& Cherryman, 2011; Read et al., 2009; Snook et al., 2012).

It is important to quickly identify vulnerable witnesses, particularly those difficult to identify (O’Mahony, Smith, \& Milne, 2011). ADHD is vulnerability more difficult to identify than most others such as intellectual impairment, despite being more common, and screening has been recommended as routine for future practice (Young et al., 2013). Researchers recommend increasing police awareness in this area via specialized training (Young, Adamou et al., 2011). Yet most youth with ADHD in forensic settings are not identified or referred, thus remaining at risk (Collins \& White, 2002; Timmi \& Taylor, 2004). Such youth continue to provide false confessions, particularly if in early rather than later adolescence, which appears to go unrecognized by police (Gudjonsson et al., 2016). ADHD appears to be 
particularly difficult to detect in offenders, as reflected in the high rate of "false-negative" screens in prison inmates as well as the low number of premorbid compared with retrospective diagnoses in this population (Young et al., 2015). Research shows even when vulnerable witnesses are identified police do not always call on appropriate support persons/intermediaries despite them being a welcome measure (Gendle \& Woodhams, 2005; Young et al., 2013).

ADHD is difficult to identify and accommodate due to comorbidity in two thirds of cases (Jensen et al., 2001). ADHD often coexists with conduct disorder, antisocial personality disorder, oppositional defiant disorder, mood disorders, intellectual impairment, learning disabilities, substance use disorders, psychopathy, and family adversity (see Gudjonsson, Sigurdsson, Sigfusdottir, \& Young, 2014; Young et al., 2013). ADHD also often coexists with fetal alcohol syndrome, which heightens suggestibility (Brown, Gudjonsson, \& Connor, 2011). Meta-analyses have shown pure ADHD, relative to pure conduct disorder, to predict higher rates of criminal acts, arrests, convictions and incarcerations (Erskine et al., 2016). Yet the risk for criminality among individuals with ADHD is increased when there is psychiatric comorbidity with conduct disorder (Knecht, de Alvaro, Martinez-Raga \& Balanza-Martinez, 2015). Some cross-sectional studies have suggested that comorbid conduct disorder and ADHD may be a separate subtype of ADHD with callous unemotional traits increasing risk for antisocial behaviour and criminality (Storebol \& Simonsen, 2016). Yet the literature broadly recognizes comorbidity in ADHD as a highly complex issue, with the unique contributions of each disorder difficult to parse out and the mechanisms of the relationship potentially mediated by confounding factors.

Of particular relevance to the investigative interviewing process, is that even in the absence of comorbidity, ADHD is associated with the greatest demands on police resources (Dalsgaard, Mortensen, Frydenberg, \& Thomsen, 2013; Gudjonsson, Sigurdsson, 
Adalsteinsson, \& Young, 2012; Young et al., 2013). With comorbidity present, it is the ADHD symptoms that are recognized as being most relevant to how the interviewee copes and if they may be prone to giving a false confession, as well as whether they give more “don’t know” responses that require further questioning (Gudjonsson et al., 2008; Gudjonsson et al., 2016).

Despite the importance of ADHD with regards to policing and the CJS, there has been surprisingly little research conducted on police perceptions of the frequency and intensity with which it impedes their work as well as their ability to recognize it. For this reason, the present study gave 46 police detectives four vignettes concerning the behaviour of witnesses and suspects with/without ADHD and asked a variety of questions. It was hypothesized that detectives would report frequent prior contact with ADHD type interviewee behaviour; high predicted risk of ADHD type interviewees having future contact with the CJS; as well as ADHD type interviewee behaviour impeding their ability to conduct interviews with time-efficiency and quality of information gathered. In this study we further hypothesized that detectives would not accurately identify ADHD as the most likely explanation of interviewee behaviour in the appropriate written vignettes.

\section{Method}

Participants. Participants were 46 police detectives. This was considered an adequate sample size given that a minimum of 20 has been recommended for factorial vignettes (Snijders, 2004), and 30 would approximate a normal distribution (Tilley, 1993). Of these detectives, 28 (60.9\%) were attending a presentation at a police academy and came from mixed backgrounds within the Criminal Investigation Branch (CIB). Another 18 (39.1\%) participants were surveyed at a Child Protection Investigation Unit CPIU meeting. There were 34 males (73.9\%) and 12 females (26.1\%). Regarding ethnicity, 45 (97.8\%) were Anglo-Australian and 1 (2.2\%) was Indigenous-Australian. Ages ranged from 26 to 55 years, 
with a mean of $39.5(S . D=6.7)$. Years of police service ranged between 5 and 30, with a mean of $14.7(S . D=6.7)$. Years served as detective or plain clothed investigator ranged between 0 and 24, with a mean of $8.4(S . D=5.9)$. The response rate for detectives approached was $95.8 \%$.

Procedure. The current study was administered in a natural work setting, matched across sessions and aligned to the nature of detective work. Administration was attached to a "vulnerable witnesses” training presentation at the police academy, and to a "youth recidivism” information session at the CPIU. This facilitated a contextual flow with natural incentives. The research purpose was explained to participants, in terms of understanding youth interviewee behaviour as well as potential gains for future detective training and outcomes. The researcher supplied each detective with a survey booklet (booklets 1-4 counterbalanced in rotating sequence). Detectives read four vignettes in each booklet, answered the Likert-type scale questions after each vignette, and answered the demographic questions. Completion time was approximately 15 minutes.

Instrumentation. The current study used four factorial vignettes. Content development drew on a literature review of tips for effective vignette writing. Consideration was given to a range of contextual and technical features (see Brown, 2008; Ganong \& Coleman, 2006; Ohan, Visser, Strain, \& Allen, 2011; Wallander, 2012). Content development addressed bias due to perception of special needs, gender, name and ethnicity as noted in the literature (see Bruchmuller, Margraf, \& Schneider, 2012; Ohan, Cormier, Hepp, Visser, \& Strain, 2008; Ohan et al., 2011). Thus, vignettes in this study referred to "the interviewee” without reference to special needs, gender, name or ethnicity. Most juvenile offenders are arrested in their teens (Snyder \& Sickmund, 2006), and police perceptions vary as a function of interviewees’ age (Wright \& Holliday, 2005). Thus, interviewee age was set at 17 years. The vignettes covered suspect and victim-witness interviewees to address 
differences in state of mind and minimize potential for bias documented regarding child and adolescent legal cases (Redlich, Ghetti, \& Quas, 2008; Sigurdsson, Gudjonsson, Einarsson, \& Gudjonsson, 2006).

Past researchers have addressed a range of content areas (Ohan et al., 2008; Ohan et al., 2011). Thus, behavioural descriptions in the vignettes addressed multiple aspects and covered full diagnostic criteria for combined type ADHD in the DSM-5 and ICD-10, noting potential for false positives (see Bruchmuller et al., 2012).

Previous literature has highlighted the importance of matching vignettes in structure, wording and readability (Ohan et al., 2011; Stolte, 2010). Each vignette had 211 words, 1112 sentences, 17.6-19.2 words per sentence, and approximately 5 characters per word, with short length recognized as optimal (Wallander, 2012). The Flesch reading ease was 48.2-52.6 and the Flesch-Kincaide reading grade level was 10.2-11.2. Research recommends a 7th/8th grader level for the average community (see Pett, Lackey, \& Sullivan, 2003) but most (84.9\%) participants held tertiary education so these scores were acceptable.

The wording and structure of the questions following each vignette were aligned with guidelines for developing surveys in the social sciences (see DeVellis, 1991; Pett et al., 2003). The question response format involved Likert-type scales, favoured for their adaptability, reliability, intuitive appeal, capacity to elicit discriminating responses, and ability to tap a range of constructs (Hodge \& Gillespie, 2003; Muraki, 1990). A ten-point Likert type scale was adopted in recognition of studies showing increasing reliability with elevated scale points (Rasmussen, 1989), the uncommon use of over ten categories (Muraki, 1990), and deliberate lack of midpoint (Ganong \& Coleman, 2006). Researchers have recommended a lack of midpoint, in order to minimise potential threats to validity and reliability (Weems \& Onwuegbuzie, 2001). Likert-type scales of this nature are highly suited to factorial design vignettes (Ohan et al., 2011; Stokes \& Schmidt, 2012). Research 
measuring police attitudes based on vignettes has successfully adopted 10-point Likert-type scales (Darwinkel, Powell, \& Tidmarsh, 2013). Anchors were simplified with "strongly disagree” to "strongly agree” as well as "no extent at all” to "enormous extent”. The literature shows additional anchors (i.e. "moderately”) as unnecessary if item wording is clear (Wakita, Ueshima, \& Noguchi, 2012).

The vignettes were counterbalanced across four booklets. Order effects were addressed to prevent the documented potential for earlier versus later items inhibiting extensive processing (Bryman, 2001; Haugtvedt \& Liu, 2010). As recommended in the literature (Brown, 2008), the booklets allowed participants to include a password in case they wanted to later withdraw participation.

A validation process was adopted for the vignettes and the questionnaire. In line with studies that have checked the ADHD diagnostic clarity of vignettes with psychologist/psychiatrists (Bruchmuller et al., 2012; Ohan et al., 2011), this study had five psychologists with Masters/PhD qualifications review all vignettes. Two detectives heavily involved in training delivery within the criminal investigation branch (CIB) and child protection unit (CPIU) also checked the vignettes and questionnaire. The psychologists and detectives all confirmed the vignettes and questionnaire adequately addressed the most important considerations.

The final booklets contained four counterbalanced vignettes describing a 17 year-old suspect/witness interviewee with ADHD/noADHD characteristics. Each vignette was followed by the same five questions with a 10-point Likert type response scale. Detectives were asked about their perceived ability to gather high quality information in a time efficient manner, past experience with this interviewee behaviour, predicted future CJS contact for this interviewee, and the degree to which a number of provided descriptions may best explain the interviewee behaviour. Descriptions included a moderate selection of common DSM-5 
diagnoses, including ADHD, as well as factors the literature commonly found detectives may assume to explain ADHD-type behaviour (i.e. non-compliance, disrespect for police, difficult temperament, etc.). In particular, mood disorders were included because research has shown that in youth offenders ADHD is most likely to be misdiagnosed as mood/affective disorders (Young et a., 2015). Conduct disorder and oppositional defiant disorder, whilst both often comorbid with ADHD, are recognized as existing on one continuum or trajectory of behavioural concerns (Salisbury, 2013). Whilst both disorders bring the individual into conflict with figures of authority, the behaviours associated with oppositional defiant disorder include less aggression and destruction to people/animals/property and more problems with emotional regulation (American Psychiatric Association, 2013). This presentation was judged to be more similar to the features of ADHD, and thus important to include in the list of possible explanations. The descriptions based on a “disorder” included a brief explanation drawing on key DSM-5 diagnostic criteria in order to minimize ambiguity and maximize response variability. Finally, each booklet included six basic demographic questions.

\section{Results}

The primary method of analyses are within-subjects 2 X 2 ANOVAs. These ANOVAs compare detectives' perceptions of either the witness or the suspect, with either the presence or absence of ADHD. ANOVAs examined detectives’ perceptions with regards to frequency of encountering interviewees with ADHD-type behaviour in their work, such interviewees' risk of future contact with the CJS, as well as impact of ADHD-type behaviour on interview time efficiency and quality. Next, one-way ANOVAs compared detectives’ perceptions of ADHD as explanation for interviewee behaviour versus nine other possibilities. The other possibilities included “typical behaviour”, “anxious”, “drugs/alcohol”, “intellectual impairment”, “difficult”, “oppositional defiant disorder”, “problems at home”, "lack of respect”, and “communication disorder”. 


\section{Detectives' Perceptions of Witnesses and Suspects, With and Without ADHD}

Table 1 outlines the means and standard deviations for the following ANOVAs, regarding detectives’ personal contact, impact on interviewing time efficiency, impact on interviewing quality of information, detectives’ perceived risk of future CJS contact, and detectives’ ability to identify ADHD.

The extent to which detectives had personally encountered ADHD behaviour in young interviewees was analyzed using a 2 X 2 ANOVA (witness/suspect X no ADHD/ADHD) with repeated measures on both factors. The means and standard deviations are displayed in Table 1. There was no main effect of witness or suspect condition, $F(1,45)=2.86, p>.05, \eta 2=.060$, or no ADHD or ADHD condition, $F(1,45)=3.99, p>.05$, $\eta 2=.081$. The interaction was also not significant, $\mathrm{F}(1,45)=3.58, \mathrm{p}>.05, \eta 2=.074$. Overall, when all conditions were combined, detectives indicated that they had personally encountered the behaviours depicted in the vignettes to a great extent $(M=7.25, S D=1.48)$. The impact of ADHD on detectives' investigative interviewing was measured using further 2 X 2 ANOVAs (witness/suspect X no ADHD/ADHD) with repeated measures on both factors. This involved measuring the impact of interview behaviour firstly on time efficiency and secondly on the quality of information gathered. Means and standard deviations are displayed in Table 1. 
Table 1

Means and Standard Deviations Across Conditions

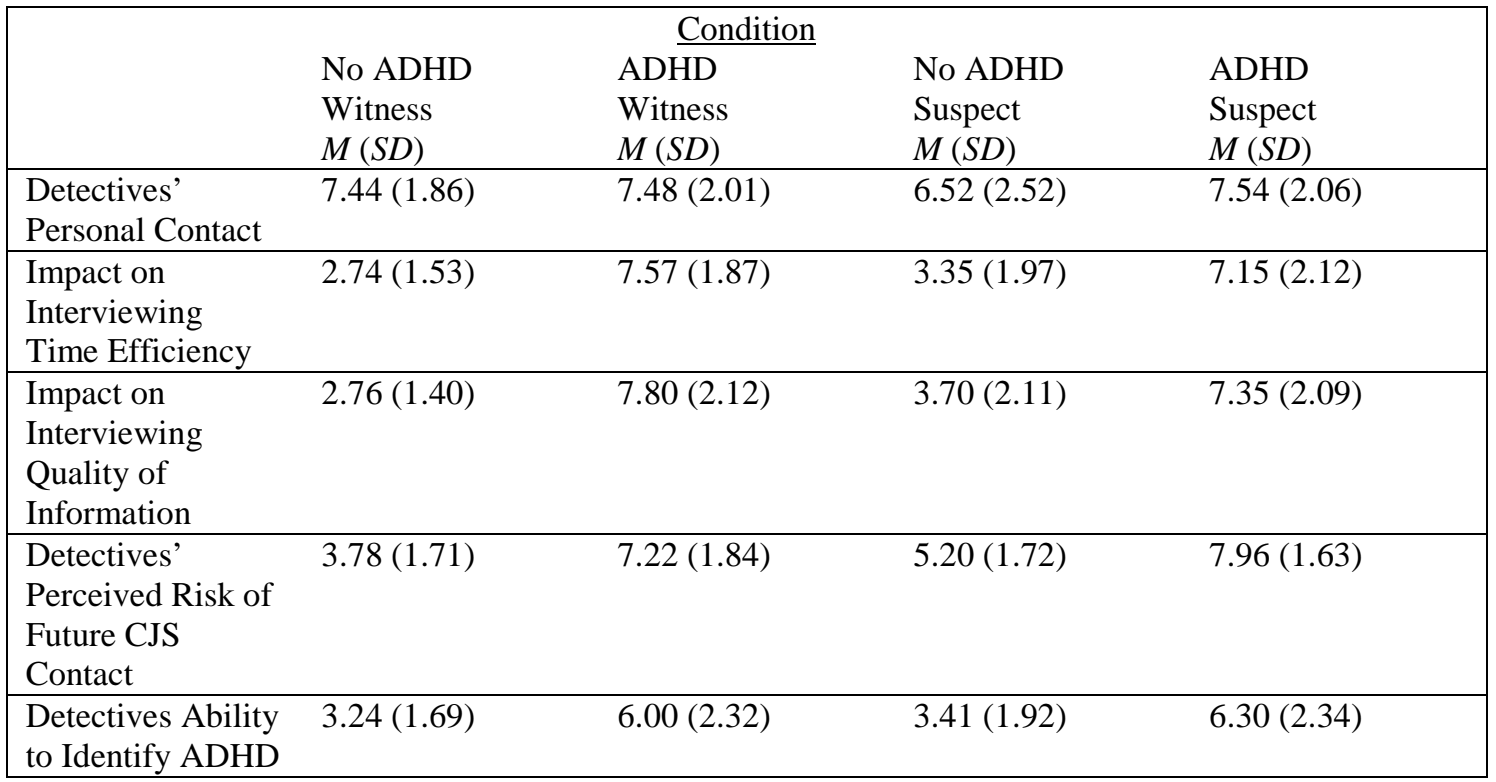

When analyzing time efficiency, there was no main effect of witness or suspect condition, $\mathrm{F}(1,45)=0.17, \mathrm{p}>.05, \eta 2=.004$. There was a significant effect of no ADHD or ADHD condition, $\mathrm{F}(1,45)=151.95, \mathrm{p}<.001, \eta 2=.772$ with the ADHD condition perceived to take much more time $(\mathrm{M}=7.36, \mathrm{SD}=1.69)$ than the no ADHD condition ( $\mathrm{M}=3.04, \mathrm{SD}=1.48)$. The interaction was also significant, $\mathrm{F}(1,45)=8.41, \mathrm{p}<.01, \eta 2=.157$. The analysis of time efficiency was followed up with six paired-samples t-tests. There was no significant difference between witness versus suspect interviewees with ADHD $(\mathrm{t}(45)=1.32, \mathrm{p}>.05)$. There was a significant difference between witness versus suspect interviewees with no ADHD $(\mathrm{t}(45)=2.16, \mathrm{p}<.05)$, with the suspect condition $(\mathrm{M}=3.35, \mathrm{SD}=1.97)$ perceived to take more time than the witness condition $(\mathrm{M}=2.74, \mathrm{SD}=1.53)$. There were highly significant differences $(\mathrm{p}<.001)$ between all other combinations comparing the ADHD versus no ADHD condition, with interviewees in the ADHD vignettes consistently perceived to take more time. Follow up plots confirmed the direction of the relationship highlighted in the ANOVA and the t-tests. 
When analyzing quality of information gathered, there was no main effect of witness or suspect condition, $\mathrm{F}(1,45)=0.98, \mathrm{p}>.05, \eta 2=.021$. There was a significant effect of no ADHD or ADHD condition, $\mathrm{F}(1,45)=169.08, \mathrm{p}<.001, \eta 2=.790$ with the ADHD condition perceived to impede the collection of quality information more $(M=7.58, S D=1.73)$ than the no ADHD condition $(\mathrm{M}=3.23, \mathrm{SD}=1.47)$. The interaction was also significant, $\mathrm{F}(1,45)=9.66$, $\mathrm{p}<.005, \eta 2=.177$. The analysis of quality of information gathered was followed up with six paired-samples t-tests. There was no significant difference between witness versus suspect interviewees with ADHD (t(45)=1.30, p>.05). There was a significant difference between witness versus suspect interviewees with no ADHD (t(45)=3.08, $<<.005)$, with the suspect condition perceived to impede the collection of quality information gathered $(\mathrm{M}=3.70, \mathrm{SD}=$ 2.11) more than the witness condition ( $M=2.76, S D=1.40)$. There were highly statistically significant differences $(\mathrm{p}<.001)$ between all other combinations comparing the ADHD versus no ADHD condition, with interviewees in the ADHD condition consistently perceived to impede the collection of quality of information more than interviewees in the no ADHD condition. Follow up plots confirmed the direction of the relationship indicated in the ANOVAs and the t-tests.

The detectives’ perceived risk of future CJS contact for interviewees was investigated using a 2 X 2 ANOVA (witness/suspect X no ADHD/ADHD) with repeated measures on both factors. The means and standard deviations are displayed in Table 1. There was a significant main effect of witness or suspect condition, $F(1,45)=25.10, p<.001, \eta 2=.358$ with the suspect condition perceived to carry greater risk of future contact ( $M=6.58$, $\mathrm{SD}=1.17)$ than the witness condition $(\mathrm{M}=5.50, \mathrm{SD}=1.09)$. There was a significant effect of no ADHD or ADHD condition, $F(1,45)=87.01, \mathrm{p}<.001, \eta 2=.659$ with the ADHD condition perceived to carry greater risk of future contact $(M=7.59, \mathrm{SD}=1.55)$ than the no ADHD 
condition $(\mathrm{M}=4.49, \mathrm{SD}=1.28)$. The interaction was not significant, $\mathrm{F}(1,45)=2.92, \mathrm{p}>.05, \eta 2=$ .061 .

Detectives’ success in identifying ADHD in the relevant vignettes was examined using a 2 X 2 ANOVA (witness/suspect X no ADHD/ADHD) with repeated measures on both factors. The means and standard deviations are displayed in Table 1 . There was no main effect of witness or suspect condition, $F(1,45)=1.33, p>.05, \eta 2=.029$. There was a significant effect of no ADHD or ADHD condition, $\mathrm{F}(1,45)=61.44, \mathrm{p}<.001, \eta 2=.577$ with the ADHD condition perceived to be highly more likely to involve ADHD (M=6.15, SD=2.17) than the no ADHD condition ( $\mathrm{M}=3.33, \mathrm{SD}=1.59)$. The interaction was not significant, $\mathrm{F}(1,45)=.21$, $\mathrm{p}>.05, \eta 2=.005$

\section{Detectives’ Ability to Identify ADHD Compared with Other Explanations}

Detectives’ ability to identify ADHD, relative to nine other possible explanations, was tested via two consecutive one-way ANOVA with repeated measures. These two ANOVAs addressed each of the two ADHD conditions in turn, including the witness and then the suspect condition. The first ANOVA, concerning the witness with ADHD condition, was significant $\mathrm{F}(1,405)=8.95, \mathrm{p}<.001, \eta 2=.166$. Planned comparisons were made between ratings for the likelihood of “ADHD” and each of the other nine explanations. A Bonferonni correction was applied ( $<$ <.0056). Compared with “ADHD” $(\mathrm{M}=6, \mathrm{SD}=2.32)$, "problems at home” $(\mathrm{M}=6.89, \mathrm{SD}=1.57)$ was a significantly higher $(\mathrm{t}(45)=3.12, \mathrm{p}<.0056)$ rated explanation, whilst “typical behaviour” $(\mathrm{M}=4.44, \mathrm{SD}=2.06)$ was a significantly lower $(\mathrm{t}(45)=3.52, \mathrm{p}<.0056)$ rated explanation of the interviewee behaviour in the witness-ADHD condition. There was no significant difference between "ADHD” (M=6, SD=2.32) and all the other explanations, including “anxious” ( $\mathrm{M}=.57, \mathrm{SD}=3.71)$, “drugs/alcohol” ( $\mathrm{M}=.87$, $\mathrm{SD}=2.57)$, “intellectual impairment” $(\mathrm{M}=.61, \mathrm{SD}=2.52)$, “oppositional defiant disorder” 
$(\mathrm{M}=.24, \mathrm{SD}=1.97)$, "lack of respect” $(\mathrm{M}=.63, \mathrm{SD}=2.65)$ and "communication disorder” $(\mathrm{M}=.13, \mathrm{SD}=2.69)$.

The second ANOVA, concerning the suspect with ADHD condition, was significant $F(1,405)=8.68, p<.001, \eta 2=.162$. Planned comparisons were made between ratings for the likelihood of "ADHD” and each of the other nine explanations. A Bonferonni correction was applied ( $\mathrm{p}<.0056)$. Compared with “ADHD” ( $\mathrm{M}=6.30, \mathrm{SD}=2.34)$, detectives were no more likely to give significantly higher or lower ratings to any of the other explanations, including “typical behaviour” (M=1.33, SD=3.18), “anxious” (M=1.04, SD=2.81), “drugs/alcohol” (M=.67, SD=2.97), “intellectual impairment” $(M=.76, \mathrm{SD}=3.06)$, “difficult” $(\mathrm{M}=.48$, $\mathrm{SD}=2.50)$, "oppositional defiant disorder” $(\mathrm{M}=.94, \mathrm{SD}=2.41)$, "problems at home” $(\mathrm{M}=.94$, $\mathrm{SD}=2.31)$, "lack of respect” ( $\mathrm{M}=.07, \mathrm{SD}=2.53)$, and "communication disorder” $(\mathrm{M}=2.83$, $\mathrm{SD}=2.50)$.

The findings of the two ANOVAs taken together show that police were not able to identify ADHD as the most likely explanation over and above the nine other possible explanations, in either the witness or suspect condition.

\section{Discussion}

This study was the first to measure police perceptions regarding contact with youth who have ADHD and the impact on their investigative interviewing, as well as their ability to recognize $\mathrm{ADHD}$ in vignettes. The findings suggest $\mathrm{ADHD}$ in youth contacting the CJS is both a prevalent and consequential problem for detectives, complicated by their difficulty identifying it. The detectives in this study report a high level of personal contact with youth displaying ADHD behaviours, in line with literature showing ADHD to be a frequently recorded diagnosis in forensic settings (Buitelaar \& Ferdinand, 2013; Lindsay et al., 2010). The detectives also perceive a high risk of future CJS contact for these interviewees, which supports literature showing ADHD to be linked to ongoing CJS contact (Young, Wells et al., 
2011). Particularly for suspects, literature has shown ADHD to be a risk factor for lifecourse-offending (Lindsay et al., 2013; Young, Wells et al., 2011) with elevated risk for boys and girls with ADHD (Dalsgaard et al., 2013). The detectives in this study perceive ADHD behaviour to significantly impede their investigative interviewing. This is inline with earlier mentioned research showing the functional deficits associated with ADHD to negatively impact detectives’ ability to use “best practice” interviewing techniques (Gudjonsson \& Sigurdsson, 2010; Vrij, Granhag \& Porter, 2010) and potentially compromise the judicial process (Collins \& White, 2002; Griffiths \& Milne, 2010; Griffiths et al., 2011; Read et al., 2009; Snook et al., 2012). It is also in-line with the earlier-mentioned research showing that such ADHD-type behaviours as depicted within the vignettes in this study, regardless of comorbidity, place the greatest demands on police resources as well as the ability of the interviewee to cope and give quality answers (Dalsgaard, Mortensen, Frydenberg, \& Thomsen, 2013; Gudjonsson, Sigurdsson, Adalsteinsson, \& Young, 2012; Young et al., 2008, 2013, 2016).

Despite interviewee ADHD behaviour representing a highly prevalent and consequential problem for police, the findings showed detectives in this study experienced difficulty identifying ADHD as a more likely explanation than other possibilities in the appropriate vignettes. Detectives rated “problems at home” significantly more likely, and "typical behaviour” as the only option significantly less likely, than "ADHD” as the explanation for victim-witness interviewees in the ADHD condition. Similarly, for the suspect ADHD condition, detectives gave high ratings to all options and there were no significant differences between “ADHD” and any of the other possible explanations. This aligns with research showing most youth with ADHD in forensic settings to go without being identified/referred (Collins \& White, 2002; Timmi \& Taylor, 2004). It has been suggested that this poor identification may be due to ineffective screening/assessment procedures during 
interviewing (Young et al., 2013), with staff knowledge, skill and training in the area failing to parallel the high rate of ADHD in the CJS (Young, Adamou et al., 2011). Researchers have suggested a need for such training to better accommodate these vulnerable interviewees and to facilitate early intervention (Belcher, 2014). The literature particularly stresses the important role of the juvenile CJS in the early identification and intervention-referral of youth with ADHD for a preventive approach (Collins \& White, 2002; DeLisi et al., 2013; Einarsson et al., 2009; Gudjonsson \& Young, 2006). The literature argues a need to address ways to facilitate such a preventive approach for particularly very young children coming into contact with the CJS in order to break the cycle (Einarsson et al., 2009; Young, Adamou et al., 2011). Researchers have suggested this may involve developing a strong identification/diagnosis system for use in the CJS (Gudjonsson \& Young, 2006; Moser \& Doreleijers, 1997) and training in this area appears highly pertinent. Overall the professional implications warrant action to address the high current and future predicted CJS contact, high impact on detective interviewing, and need for better awareness/identification, regarding youth with ADHD.

There were potential limitations to the current study. A larger sample size may have offered increased power and greater flexibility for additional analyses such as CIB versus CPIU comparisons. Given the relatively small convenience sample, their may be limited ability to generalize the current findings to a broader range of police. Furthermore, the use of written vignettes may have provided limited contextual information for detectives to make judgments as accurately as they might in the field. Some researchers have criticized vignettes as over-simplified, failing to capture important social nuances, as well as prone to "vignette equivalence” and tied responses (King \& Wand, 2007; Ludwick et al., 2004; Ludwick \& Zeller, 2001; Ohan et al., 2011). This study minimized such effects by utilizing an optimal number (four) of factorial vignettes, and noted the expansive body of literature in support of factorial vignettes that outweighed such criticisms. Many researchers argue factorial vignettes 
to be an advantageous way of collecting data due to their application to highly challenging and sensitive situations, their usefulness for determining where specific action is necessary, as well as their ability to encourage reflective higher-order thinking (Collett \& Childs, 2011; Ganong \& Coleman, 2006; Kish, 2007; Lee, 1993; Ludwick et al., 2004; Kish, 2007; Stokes \& Schmidt, 2012). Vignettes have successfully been applied to a range of fields (see Collett \& Childs, 2011; Poulou, 2001; Twemlow, Fonagy, Sacco, \& Vernberg, 2008; Stolte, 2010); to criminality issues (Ohan et al., 2011; Tolsma \& Blaauw, 2012); and in particular ADHD (Morris, 2005; Ohan et al., 2011). Factorial design vignettes are recognized as one of the most advanced instruments for measuring judgement and decision-making (Lauder, 2002; Wallander, 2012); offering high internal and external validity (Ganong \& Coleman, 2006; Ludwick \& Zeller, 2001); high statistical power (Stokes \& Schmidt, 2012); consideration to the effects of respondent characteristics (Taylor, 2006); as well as flexibility/control over the number of scenarios presented (3 to 30) and dimensions manipulated (2 to 15) (Ganong \& Coleman, 2006).

Another potential limitation relates to the validity of the vignettes. Whilst great effort was extended to ensure that the behaviour of the interviewees with ADHD was described in close alignment with DSM-5 diagnostic criteria, it may be difficult to definitively rule out these behaviours also reflecting other disorders known to be highly comorbid with ADHD such as oppositional defiant disorder or conduct/antisocial personality disorder. There appears to be a lack of empirical research describing how the behaviour of juvenile witness/victims or suspects with ADHD and such comorbid disorders may present. Ensuring a pure description of ADHD, free of comorbidity, was controlled for as much as possible by having psychologists vet the vignettes. The authors do note however that whilst these psychologists possessed postgraduate training and experience working with youth with ADHD, they were not experts in the field of ADHD. 
Another potential limitation relates to the questions regarding the vignettes. Specifically, the list of options for detectives to rate as the most likely explanation of interviewee behaviour in each vignette could have been more inclusive. The literature has highlighted strong comorbidity between ADHD and conduct disorder, and between ADHD and oppositional defiant disorder. Researchers have highlighted conduct disorder and oppositional defiant disorder as existing on a continuum of behavioural concerns (Salisbury, 2013), and so oppositional defiant disorder was chosen as the most extreme presentation matched to juvenile youth. However, additionally including conduct disorder as an added option may have enhanced fidelity of the research design.

A further potential limitation is the complication caused by comorbidity. Some researchers have found hyperactive youth without comorbid diagnoses to be at no greater risk of criminality or recidivism than those with other emotional/behavioural disorders such as conduct disorder (Grieger \& Hosser, 2012; Mordre, Groholt, Kielsberg, Sandstad, \& Myhre, 2011; Satterfield et al., 2007). Yet these studies’ limitations included insufficient power, limited probands, missing values, high drop out rates, insufficient parameter-defining information, restricted age ranges, unreliable records, low participant literacy, inapplicable samples, as well as over reliance on self-report measures and retrospective accounts (Grieger \& Hosser, 2012; Gudjonsson et al., 2014; Mordre et al., 2011). Furthermore, research has shown it is the impulsive, inattentive and poor self-control dimensions of ADHD putting them at greatest risk of criminality (Eme, 2012, 2013, 2014; Gudjonsson et al., 2010; Moffitt, Poulton \& Caspi, 2013; Zhou et al., 2014). Researchers have also argued ADHD to be the precipitating factor leading to the trajectory of comorbidity (Beauchaine, Hinshaw, \& Pang, 2010; Beauchaine \& McNulty, 2013; Beauchaine et al., 2013), and as noted previously it is ADHD that is the most demanding of police resources (Young et al., 2013). A study of 25,000 participants found a significant reduction in offending after introducing stimulant 
medication, with no difference depending on coexisting diagnoses such as conduct, oppositional-defiant, antisocial personality or substance use disorders (Lichenstein et al., 2012). This establishes value in early identification and intervention targeting ADHD, with or without comorbidity. There is no doubt ADHD and comorbidity is a complex association (Vogel, 2014) but the functional deficits associated with ADHD regardless of comorbidity should not be ignored. So consequential are the deficits that researchers have proposed courts rule ADHD a mitigating factor in criminal hearings (Eme, 2012, 2013, 2014; Pope, Luna, \& Thomas, 2012).

The findings of the current study offer a solid rationale for future research to explore this important topic. In particular, it is recommended that the focus be on awareness and training needs. It is worthwhile to pursue research that directly surveys police about their knowledge and skill regarding how to recognize, screen, accommodate and refer for early intervention those youth suspected to have ADHD. It is also recommended to investigate how detectives would specifically like to advance their expertise in this area, what features they would like to see in a training program, and how this may transcend to a psycho-educational intervention.

In conclusion, the current study showed detectives to perceive that they have frequent contact with interviewees displaying ADHD behavioural characteristics, that it significantly impedes their ability to conduct time-efficient high quality interviews, and that these interviewees are at significant risk of continued CJS contact. This study also showed that detectives could not identify ADHD as the most likely explanation over and above other possibilities. These findings suggest a strong need for action to help raise police awareness of ADHD and its implications, as well as to address police training regarding early identification and early intervention of youth with probable ADHD. 


\section{References}

American Psychiatric Association. (2013). Diagnostic and statistical manual of mental disorders ( $5^{\text {th }}$ ed). Arlington, VA: American Psychiatric Publishing

Bala, N., Lee, J., \& McNamara, E. (2001). Children as witnesses: Understanding their capacities, needs, and experiences. Journal of Social Distress and the Homeless, 10(1), 41-68.

Barkley, R. A. (2015). Attention-deficit hyperactivity disorder: A handbook for diagnosis and treatment (4th ed.). New York: Guilford Publications Inc.

Beauchaine, T. P., Gatzke-Kopp, L., Neuhaus, E., Chipman, J., Reid, M. J., \& WebsterStratton, C. (2013). Sympathetic- and parasympathetic-linked cardiac function and prediction of externalizing behavior, emotion regulation, and prosocial behavior among preschoolers treated for ADHD. Journal of Consulting \& Clinical Psychology, 81(3), 481-493.

Beauchaine, T. P., Hinshaw, S. P., \& Pang, K. L. (2010). Comorbidity of Attention Deficit/Hyperactivity Disorder and Early-Onset Conduct Disorder: Biological, Environmental \& Developmental Mechanisms. Clinical Psychology: Science \& Practice, 7(4), 327-337.

Beauchaine, T. P., \& McNulty, T. (2013). Comorbidities and continuities as ontogenic processes: Toward a developmental spectrum model of externalizing psychopathology. Development \& Psychopathology, 25(4), 1505-1528.

Belcher, J. R. (2014). Attention deficit hyperactivity disorder in offenders and the need for early intervention. International Journal of Offender Therapy and Comparative Criminology, 58(1), 27-40.

Brown, A. (2008). Vignettes to assess healthcare staff perceptions of risk. Nurse Researcher, 15(2), 30-39. 
Brown, N. N., Gudjonsson, G., \& Connor, P. (2011). Suggestibility and fetal alcohol spectrum disorders: I'll tell you anything you want to hear. The Journal of Psychiatry \& Law, 39(1), 39-71.

Brubacher, S. P., Glisic, U., Roberts, K. P., \& Powell, M. (2011). Children’s ability to recall unique aspects of one occurrence of a repeated event. Applied Cognitive Psychology, 25, 351-358.

Bruchmuller, K., Margraf, J., \& Schneider, S. (2012). Is ADHD diagnosed in accord with diagnostic criteria? Overdiagnosis and influence of client gender on diagnosis. Journal of Consulting and Clinical Psychology, 80(1), 128-138.

Bryman, A. (2001). Social research methods. Oxford: Oxford University Press.

Buitelaar, N. J., \& Ferdinand, R. F. (2013). ADHD undetected in criminal adults. Journal of Attention Disorders, Jan, 25.

Collett, J. L., \& Childs, E. (2011). Minding the gap: Meaning, affect, and the potential shortcomings of vignettes. Social Science Research, 40, 513-522.

Collins, P., \& White, T. (2002). Forensic implications of attention deficit hyperactivity disorder (ADHD) in adulthood. The Journal of Forensic Psychiatry, 13(2), 263-284.

Dalsgaard, S., Mortensen, P., Frydenberg, M., \& Thomsen, P. (2013). Long-term criminal outcome of children with attention deficit hyperactivity disorder. Criminal Behaviour and Mental Health, 23, 86-98.

Darwinkel, E., Powell, M., \& Tidmarsh, P. (2013). Improving police offers’ perceptions of sexual offending through intensive training. Criminal Justice Behaviour, 40, 897910.

DeLisi, M., Neppl, T. K., Lohman, B. J., Vaughn, M. G., \& Shook, J. J. (2013). Early starters: Which type of criminal onset matters most for delinquent careers? Journal of Criminal Justice, 41, 12-17. 
DeVellis, R. F. (1991). Scale development: Theory and applications. Newbury Park, CA: Sage.

Einarsson, E., Sigurdsson, J. F., Gudjonsson, G. H., Newton, A. K., \& Bragason, O. O. (2009). Screening for attention-deficit hyperactivity disorder and co-morbid mental disorders among prison inmates. Nordic Journal of Psychiatry, 63(5), 361-367.

Eme, R. (2012). ADHD: An integration with pediatric traumatic brain injury. Expert Review of Neurotherapeutics, 12, 1275-1283.

Eme, R. (2014). Attention deficit hyperactivity disorder: A mitigation of criminal responsibility? Journal of Forensic Psychology Practice, 14(3), 221-236.

Eme, R. (2013). Attention-deficit/ hyperactivity disorder and criminal behavior. International Journal of Sociology Study, 1, 29-36.

Erskine, H. E., Norman, R. E., Ferrari, A. J., Chan, G. C. K., Copeland, W. E., Whiteford, H. A., \& Scott, J. G. (2016). Long-term outcomes of attention-deficit/hyperactivity disorder and conduct disorder: A systematic review and meta-analysis. Journal of the American Academy of Child \& Adolescent Psychiatry, 55(10), 841-850.

Ganong, L. H., \& Coleman, M. (2006). Multiple segment factorial vignette designs. Journal of Marriage and Family, 68, 455-468.

Gendle, K., \& Woodhams, J. (2005). Suspects who have a learning disability. Journal of Intellectual Disabilities, 9(1), 70-81.

Ginsberg, Y., Hirvikoski, T., \& Lindefors, N. (2010). Attention Deficit Hyperactivity Disorder (ADHD) among longer-term prison inmates is a prevalent, persistent and disabling disorder. BioMed Central Psychiatry, 10, 112-125.

Ginsberg, Y., Langstrom, N., Larsson, H., \& Lichtenstein, P. (2013). ADHD and criminality: Could treatment benefit prisoners with ADHD who are at higher risk of reoffending? Expert Review of Neurotherapeutics, 13(4), 345-350. 
Goldstein, S. (1997). Attention-Deficit/Hyperactivity Disorder. FBI Law Enforcement Bulletin, 66(6), 11-17.

Grieger, L., \& Hosser, D. (2012). Attention deficit hyperactivity disorder does not predict criminal recidivism in young adult offenders: Results from a prospective study. International Journal of Law and Psychiatry, 35(1), 27-34.

Griffiths, A., \& Milne, R. (2010). The application of the cognitive interview techniques as part of an investigation. In C.A. Ireland \& M. J. Fisher (Eds.), Consultancy and advising in forensic practice: Empirical and practical guidelines (pp. 71-90). Chichester, England: Wiley.

Griffiths, A., Milne, B., \& Cherryman, J. (2011). A question of control? The formulation of suspect and witness interview question strategies by advanced interviewers. International Journal of Police Science \& Management, 13(3), 255-268.

Gudjonsson, G. H. (2012). False confessions and correcting injustices. New England Law Review, 46, 689-709.

Gudjonsson, G. H. (2010). Psychological vulnerabilities during police interviews. Why are they important? Legal and Criminological Psychology, 15, 161-175.

Gudjonsson, G. H., \& Sigurdsson, J. F. (2010). The relationship of compliance with inattention and hyperactivity/impulsivity. Personality \& Individual Differences, 49(6), 651-654.

Gudjonsson, G. H., Sigurdsson, J. F., Adalsteinsson, T. F., \& Young, S. (2012). The relationship between ADHD symptoms, mood instability, and self-reported offending. Journal of Attention Disorders, 17(4), 339-346.

Gudjonsson, G. H., Sigurdsson, J. F., Bragason, O. O., Newton, A. K., \& Einarsson, E. (2008). Interrogative suggestibility, compliance and false confessions among 
prisoners and their relationship with attention deficit hyperactivity disorder (ADHD) symptoms. Psychological Medicine, 38(7), 1037-1044.

Gudjonsson, G. H., Sigurdsson, J. F., Einarsson, E., Bragason, O. O., \& Newton, A. K. (2010). Inattention, hyperactivity/impulsivity and antisocial personality disorder. Which is the best predictor of false confessions? Personality and Individual Differences, 48, 720-724.

Gudjonsson, G. H., Sigurdsson, J. F., Sigfusdottir, I. D., Asgeirsdottir, B. B., González, R., \& Young, S. (2016). A national epidemiological study investigating risk factors for police interrogation and false confession among juveniles and young persons. Social Psychiatry and Psychiatric Epidemiology, 51, 359-367.

Gudjonsson, G. H., Sigurdsson, J. F., Sigfusdottir, I. D., \& Young, S. (2014). A national epidemiological study of offending and its relationship with ADHD symptoms and associated risk factors. Journal of Attention Disorders, 18(1), 3-13.

Gudjonsson, G. H., Sigurdsson, J. F., Sigfusdottir, I. D., \& Young, S. (2011). False confessions to police and their relationship with conduct disorder, ADHD and life adversity. Personality and Individual Differences, 52, 696-701.

Gudjonsson, G. H., Wells, J., \& Young, S. (2011). Motivation for offending among prisoners and the relationship with Axis I and Axis II disorders and ADHD symptoms. Personality and Individual Differences, 50, 64-68.

Gudjonsson, G. H., \& Young, S. (2006). An overlooked vulnerability in a defendant: Attention deficit hyperactivity disorder and a miscarriage of justice. Legal and Criminological Psychology, 11, 211-218.

Gudjonsson, G. H., Young, S., \& Bramham, J. (2007). Interrogative suggestibility in adults diagnosed with attention-deficit hyperactivity disorder (ADHD). A potential 
vulnerability during police questioning. Personality and Individual Differences, 43, 737-745.

Haugtvedt, C., \& Liu, K. (2010). Order Effects. In Neil J. Salkind (Ed.), Encyclopedia of Research Design. (pp. 974-976). Thousand Oaks, CA: SAGE Publications, Inc. doi: http://dx.doi.org.libraryproxy.griffith.edu.au/10.4135/9781412961288.n293

Hodge, D. R., \& Gillespie, D. (2003). Phrase completions: An alternative to Likert scales. Social Work Research, 27(1), 45-55.

Howard, R., \& Seok Hong, Ng. (2002). Effects of metamotivational state and coping style on interrogative suggestibility. Personality and Individual Differences, 33, 479-485.

Jensen, P. S., Hinshaw, S. P., Kraemer, H. C., Lenora, N., Newcorn, J. H., Abikoff, H. B., et al. (2001). ADHD comorbidity findings from the MTA study: Comparing comorbid subgroups. Journal of American Academy of Child \& Adolescent Psychiatry, 40, 147-158.

Kebbell, M.R., \& Wagstaff, G.F. (1996) Eyewitness confidence and accuracy: Is it dependent on item difficulty? British Journal of Psychology, 87, 653-662.

Kebbell, M R., Milne, R., \& Wagstaff, G. F. (1999). The cognitive interview: A survey of its forensic effectiveness. Psychology, Crime, \& Law, 5, 101-115.

King, G., \& Wand, J. (2007). Comparing incomparable survey responses: Evaluating and selecting anchoring vignettes. Political Analysis, 15(1), 46-66.

Kish, M, H. Z. (2007). Overview of using vignettes to develop higher order thinking and academic achievement in adult learners in an online learning environment. Technology Education, 2(3), 60-74.

Knecht, C., de Alvaro, R., Martinez-Raga, J., \& Balanza-Martinez, V. (2015). Attentiondeficit hyperactivity disorder (ADHD) substance use disorders, and criminality: A 
difficulty problem with complex solutions. International Journal of Adolescent Medicine and Health, 27(2), 163-175.

Lambie, I., Ione, J., Randell, I., \& Seymour, F. (2013). Offending behaviours of child and adolescent firesetters over a 10-year follow up. Journal of Child Psychology and Psychiatry, and Allied Disciplines, 54(12), 1295-1307.

Lauder, W. (2002). Factorial survey methods: A valuable but under-utilized research method in nursing research? Nursing Times Research, 7(1), 35-43.

Lee, R. M. (1993). Doing research on sensitive topics. London: Sage.

Lichenstein, P., Halldner, L., Zettergvist, J., Sjolander, A., Serlachius, E., Fazel, S.

Langstrom, N., \& Larsson, H. (2012). Medication for attention deficit-hyperactivity disorder and criminality. New England Journal of Medicine, 367(21), 2006-2014.

Lindsay, W. R., Carson, D., Holland, A. J., Taylor, J. L., O’Brien, G., \& Wheeler, J. R.

(2013). The impact of known criminogenic factors on offenders with intellectual disability: Previous findings and new results on ADHD. Journal of Applied Research in Intellectual Disabilities, 26, 71-80.

Lindsay, W. R., O’Brien, G., Carson, D., Holland, A. J., Taylor, J. L., Wheeler, J. R., Middleton, C., Price, K., Steptoe, L., \& Johnston, S. (2010). Pathways into services for offenders with intellectual disabilities: Childhood experiences, diagnostic information, and offense variables. Criminal Justice and Behavior, 37(6), 678-694.

Ludwick, R., Wright, M. E., Zeller, R. A., Dowding, D. W., Lauder, W., \& Winchell, J. (2004). An improved methodology for advancing in nursing research: Factorial surveys. Advances in Nursing Science, 27, 224-238.

Ludwick, R., \& Zeller, R. A. (2001). The factorial survey: An experimental method to replicate real world problems. Nursing Research, 50(2), 129-133. 
McArdle, P. (2004). Attention-deficit hyperactivity disorder and life-span development. British Journal of Psychiatry, 184, 468-469.

Milne, R., \& Bull, R. (2003). Does the cognitive interview help children to resist the effects of suggestive questioning? Legal and Criminological Psychology, 8(1), 21-38.

Milne, R., Sharman, S. J., Powell, M. B., \& Mead, S. (2013). Assessing the effectiveness of the cognitive interview for children with severe intellectual disabilities. International Journal of Disability, Development and Education, 60(1), 18-29.

Moffitt, T. E., Poulton, R., \& Caspi, A. (2013). Lifelong impact of early self-control: Childhood self-discipline predicts adult quality of life. American Scientist, 101(5), 352-362.

Mohr-Jensen, C., \& Steinhausen, H. (2016). A meta-analysis and systematic review of the risks associated with childhood attention-deficit hyperactivity on long-term outcome of arrests, convictions and incarcerations. Clinical Psychology Review, 48, 32-42.

Mordre, M., Groholt, B., Kielsberg, E., Sandstad, B., \& Myhre, A. M. (2011). The impact of ADHD and conduct disorder in childhood on adult delinquency: A 30 years followup study using official crime records. BMC Psychiatry, 1, 57-67.

Morris, M. (2005). Vignette on Tommy. Preventing School Failure, 49(4), 63-64.

Moser, F., \& Doreleijers, T. A. H. (1997). An explorative study of juvenile delinquents with attention/hyperactivity disorder. European Journal on Criminal Policy and Research, 5(2), 67-81.

Muraki, E. (1990). Fitting a polytomous item response model to Likert-type data. Applied Psychological Measurement, 14, 59-71.

Ohan, J. L., Cormier, N., Hepp, S. L., Visser, T. A. W., \& Strain, M. C. (2008). Does knowledge about attention-deficit/hyperactivity disorder impact teachers' reported behaviors and perceptions? School Psychology Quarterly, 23(3), 436-449. 
Ohan, J. L., Visser, T. A. W., Strain, M. C., \& Allen, L. (2011). Teachers’ and education students' perceptions of and reactions to children with and without the diagnostic label “ADHD”. Journal of School Psychology, 49, 81-105.

O’Mahony, B. M., Smith, K., \& Milne, R. (2011). The early identification of vulnerable witnesses prior to an investigative interview. The British Journal of Forensic Practice, 13(2), 114-123.

Pett, M. A., Lackey, N. M., \& Sullivan, J. J. (2003). Making sense of factor analysis: The use of factor analysis for instrument development in health care research. Thousand Oaks, CA: Sage.

Pope, K., Luna, B., \& Thomas, C. (2012). Developmental neuroscience and the courts: How science is influencing the disposition of juvenile offenders. Journal of the American Academy of Child and Adolescent Psychiatry, 51, 341-342.

Polanczyk, G., de Lima, M. S., Horta, B. L., Biederman, J., Rohde, L.A. (2007). The worldwide prevalence of ADHD: A systematic review and meta-regression analysis. American Journal of Psychiatry, 164, 942-8.

Poulou, M. (2001). The role of vignettes in the research of emotional and behavioural difficulties. Emotional and Behavioural Difficulties. 6(1), 50-62.

Powell, M. B., \& Lancaster, S. (2003). Guidelines for interviewing children during child custody evaluations. Australian Psychologist, 38(1), 46-54.

Powell, M. B., \& Snow, P. M. (2007). Guide to questioning children during the free narrative phase of an investigative interview. Australian Psychologist, 42(1), 57-65.

Powell, M. B., \& Thomson, D. M. (1997). Contrasting memory for temporal-source and memory for content in children's discrimination of repeated events. Applied Cognitive Psychology, 11, 339-360. 
Rasmussen, J. L. (1989). Analysis of Likert-scale data: A reinterpretation of Gregoire and Driver. Psychological Bulletin, 105(1), 167-170.

Read, J. M., Powell, M. B., Kebbell, M. R., \& Mine, R. (2009). Investigative interviewing of suspected sex offenders: A review of what constitutes best practice. International Journal of Police Science \& Management, 11(4), 442-459.

Redlich, A. D., Ghetti, S., \& Quas, J. A. (2008). Perceptions of children during a police interview: A comparison of alleged victims and witnesses. Journal of Applied Social Psychology, 38(3), 705-735.

Salisbury, T. (2013). The relationship between Oppositional Defiant Disorder, Conduct Disorder, Antisocial Personality Disorder and Psychopathy: A proposed trajectory. Western Undergraduate Psychology Journal, 1(1), 1-9.

Satterfield, J. H., Faller, K. J., Crinella, F. M., Schell, A. M., Swanson, J. M., \& Homer, L. D. (2007). A 30-Year prospective follow-up study of hyperactive boys with conduct problems: Adult criminality. Journal of the American Academy of Child and Adolescent Psychiatry, 46(5), 601-610.

Sigurdsson, J. F., \& Gudjonsson, G. H. (2001). False confessions: The relative importance of psychological, criminological and substance abuse variables. Psychology, Crime and Law, 7, 275-289.

Sigurdsson, J. F., Gudjonsson, G. H., Einarsson, E., \& Gudjonsson, G. (2006). Differences in personality and mental state between suspects and witnesses immediately after being interviewed by the police. Psychology, Crime and Law, 12, 619-628.

Simon, V., Czobor, P., Balint, S., Meszaros. A., \& Bitter, I. (2009). Prevalence and correlates of adult attention-deficit hyperactivity disorder: Meta-analysis. British Journal of Psychiatry 194, 204-11. 
Snijders, T. A. B. (2004). Multilevel analysis. In M. S. Lewis-Beck, A. Bryman, \& T. Futing Liao (Eds.), The SAGE encyclopedia of social science research methods (pp. 673677). Thousand Oaks, CA: SAGE.

Snook, B., Luther, K., Quinlan, H., \& Milne, R. (2012). Let 'em talk: A field study of police questioning practices of suspects and accused persons. Criminal Justice and Behavior, 39, 1328-1339.

Snyder, H. N., \& Sickmund, M. (2006). Juvenile offenders and victims: 2006 national report. Washington, DC: Department of Justice, Office of Justice Programs, Office of Juvenile Justice and Delinquency Prevention.

Sparrow, E. P., \& Erhardt, D. (2014). Essentials of ADHD assessment for children and adolescents. Hoboken, NJ: John Wiley \& Sons Inc.

Stokes, J., \& Schmidt, G. (2012). Child protection decision making: A factorial analysis using case vignettes. Social Work, 57(1), 83-90.

Stolte, J. F. (2010). The context of satisficing in vignette research. The Journal of Social Psychology, 134(6), 727-733.

Storebol, O. J., \& Simonsen, E. (2016). The Association Between ADHD and Antisocial Personality Disorder (ASPD): A Review. Journal of Attention Disorders, 20(10), 815-824.

Taylor, B. J. (2006). Factorial surveys: Using vignettes to study professional judgement. British Journal of Social Work, 36, 1187-1207.

Thapar, A., \& Cooper, M. (2016). Attention deficit hyperactivity disorder. Lancet, 387, 1240 1250.

Tilley, A. (1993). An introduction to psychological research and statistics ( $2^{\text {nd }}$ ed). Brisbane, QLD: Pineapple Press. 
Timmi, S., \& Taylor, E. (2004). ADHD is best understood as a cultural construct. British Journal of Psychiatry, 184, 8-9.

Tolsma, J., \& Blaauw, J. (2012). When do people report crime to the police? Results from a factorial survey design in the Netherlands, 2010. Journal of Experimental Criminology, 8, 117-134.

Twemlow, S. W., Fonagy, P., Saaco, F. C., \& Vernberg, E. (2008). Assessing adolescents who threaten homicide in schools. Journal of Clinical Social Work, 36, 131-142.

Vogel, M. (2014). Mental illness and criminal behaviour. Sociology Compass, 8(4), 337-346.

Vrij, A., Granhag, P. A., \& Porter, S. (2010). Pitfalls and opportunities in nonverbal and verbal lie detection. Psychological Sciences in the Public Interest, 11, 89-129.

Wakita, T., Ueshima, N. \& Noguchi, H. (2012). Psychological distance between categories in the Likert scale: Comparing different numbers of options. Educational and Psychological Measurement, 72, 533-546.

Wallander, L. (2012). Measuring social workers’ judgements: Why and how to use the factorial survey approach in the study of professional judgements. Journal of Social Work, 12(4), 364-384.

Weems, G. H., \& Onwuegbuzie, A. J. (2001). The impact of midpoint responses and reverse coding on survey data. Measurement and Evaluation in Counseling and Development, 34(3), 166-176.

Wright, A., \& Holliday, R. E. (2005). Police officers’ perceptions of older eyewitnesses. Criminological Psychology, 10, 211-223.

Young, S. (2005). Coping strategies used by ADHD adults. Personality and Individual Differences, 38, 809-816.

Young, S. J., Adamou, M., Bolea, B., Gudjonsson, G., Muller, U., Pitts, M., \& Thome, J. (2011). The identification and management of ADHD offenders within the criminal 
justice system: A consensus statement from the UK Adult ADHD Network and criminal justice agencies. BMC Psychiatry, 11(1), 32-45.

Young, S., Goodwin, E. J., Sedjwick, O., \& Gudjonsson, G. H. (2013). The effectiveness of police custody assessments in identifying suspects with intellectual disabilities and attention deficit hyperactivity disorder. BMC Medicine, 11, 248-259.

Young, S., \& Gudjonsson, G. H. (2005). Neuropsychological correlates of the YAQ-S and YAQ-I self- and informant-reported ADHD symptomology, emotional and social problems and delinquent behavior. British Journal of Clinical Psychology, 44, 4757.

Young, S., \& Gudjonsson, G. H. (2007). ADHD symptomology and its relationship with emotional, social and delinquency problems. Psychology, Crime \& Law, 12(5), 463471.

Young, S., \& Gudjonsson, G. H. (2008). Growing out of ADHD: The relationship between functioning and symptoms. Journal of Attention Disorders, 12, 162-169.

Young, S., Wells, J., \& Gudjonsson, G. H. (2011). Predictors of offending among prisoners: The role of attention-deficit hyperactivity disorder and substance use. Journal of Psychopharmacology, 25(11), 1524-1532.

Young, S., Moss, D., Sedgwick, O., Fridman, M., \& Hodgkins, P. (2015). A meta-analysis of the prevalence of attention deficit hyperactivity disorder in incarcerated populations Psychological Medicine, 45, 247-58.

Young, S., Sedgwick, O., Fridman, M., Gudjonsson, G., Hodgkins, P., Lantigua, M., \& González, R. A. (2015). Co-morbid psychiatric disorders among incarcerated ADHD populations: A meta-analysis. Psychological Medicine, 45, 2499-2510. 
Zhou, J., Witt, K., Chen, C., Zhang, S., Zhang, Y., Qiu, C., Cao, L., \& Wang, X. (2014). High impulsivity as a risk factor for the development of internalizing disorders in detained juvenile offenders. Comprehensive Psychiatry, 55, 1157-1164.

The authors acknowledge the assistance provided by the Queensland Police Service. The views expressed in this material are those of the authors and are not those of the Queensland Police Service. Responsibility for any errors of omission or commission remains with the authors. The Queensland Police Service expressly disclaims any liability for any damage resulting from the use of the material contained in this publication and will not be responsible for any loss, howsoever arising, from use of or reliance on this material.

This project did not receive any specific grant from funding agencies in the public, commercial, or not-for-profit sectors. Author A currently receives financial support via an Australian Government Research Training Program Scholarship. 